\title{
Possible Health Implications Associated with Cosmetics: A Review
}

\author{
Okereke J. N.", Udebuani A. C., Ezeji E. U., Obasi K. O., Nnoli M. C. \\ School of Biological Sciences, Federal University of Technology, Owerri, Imo State, Nigeria

\section{Email address:} \\ kayboy2013@live.com (Obasi K. O), ucheezeji@yahoo.com (Ezeji E.U), chibufo@yahoo.com (Udebuani A. C.), \\ revdavidmcn@yahoo.com (Nnoli M. C.), chinwendubueze1@yahoo.com (Okereke J. N.)
}

\section{To cite this article:}

Okereke J. N., Udebuani A. C., Ezeji E. U., Obasi K. O., Nnoli M. C. Possible Health Implications Associated with Cosmetics: A Review. Science Journal of Public Health. Special Issue: Who Is Afraid of the Microbes. Vol. 3, No. 5-1, 2015, pp. 58-63. doi: 10.11648/j.sjph.s.2015030501.21

\begin{abstract}
Cosmetics are products applied to the body or face to improve appearance. Theycleanse, beautify, promote attractiveness and alter appearance of the body. The concept of beauty and cosmetics is as old as mankind and civilization. Assorted beauty products such as skincare products, hair products, fragrances, oral hygiene, and nail products, which may contain toxic chemicals that can be harmful to health are used especially by women. Most cosmetic products contain hazardous chemicals like Sodium Laureth Sulphate, Talcum, Parabens, Coal tar dye, Phthalates, Fragrance, Mineral oil, Triethanolamine and some heavy metals eg, Lead, Arsenic, Nickel, Cadmium, and Mercury. The bioaccumulation of theseharmful chemicals andmetals in the body over time has been associatedwith cancer, reproductive and developmental disorders, contact dermatitis, hair loss, lung damage, ageing, skin disease and reaction, allergies, and damage of nails. The deleterious chemicals and metals can enter into the body by inhalation of perfumes, deodorant, nail polish, scented powder, etc; by absorption through penetration of harmful chemicals from body creams, moisturizers, cleanser, eye shadow, etc. It can also be by ingestion of chemicals and metals in lip sticks, lip balm, lip gloss, etc. through the mouth.
\end{abstract}

Keywords: Health, Implications, Hazards, Cosmetics, Chemicals, Metals

\section{Introduction}

Cosmetics are products applied to the body for the purpose of beautifying, cleansing or improving appearance and enhancing attractive features [1]. They include a range of products such as tooth paste, shampoo, conditioners, mascara, after shave lotion, styling gel, creams, lotions, powders, perfumes, lipsticks, fingernail and toenail polish, eye and facial make-ups, permanent waves, hair colours, hair sprays and deodorants. According to [2] 'make up'is classified as subset of cosmetics that has to do with beautifying of the face. Schneider et al., [3] defined skincare products or cosmetics as mixtures of synthetic or natural chemical compounds used to improve the appearance or smell of the body. They arearticles intended to be rubbed, poured, sprinkled or sprayed on, introduced into, or otherwise applied to the human body or any part thereof for promoting attractiveness, cleansing, beautifying or altering the appearance without affecting the body structure or functions.
The use of cosmetics dates back to around 10000BC [4]. Many of the present-day beauty rituals such as hair colouration, depilation and exfoliation find their roots in ancient Egyptian culture [5]. In the olden days, the Romans, Greeks and Egyptians used various cosmetics which contain white Lead and Mercury [2]. Scented oils and ointments were used to clean and soften the skin and mask body odour while dyes and natural paints were used to colour the face, mainly for ceremonial and religious occasions [4]. According to [2], there is a common ancient belief that eye makeup could ward off evil spirits and improve sight.

The use of cosmetics today cuts across people of all spheres of life. Facial cosmetics are a necessity in the entertainment industry where hundreds of new recruits are daily added to the huge number of cosmetics users with little or no knowledgeof their side effects. Some of the cosmetics used contain different compounds like zincite, cuprite goethite, amorphous carbon, elemental silicon or talc hematite, minimumorganic compounds, and even heavy metals such as Lead $[6,7]$. Black Antimony which was used 
as eyeliner in ancient Egypt [8] is still being used by peoplein NorthernNigeria [9]. It is locally known as "Tiro, Otanjele,and Buje," in the three major languages in Nigeria [10]. Antimony ( $\mathrm{Sb})$, is white in colour and moreshining than Silver; containing $81 \%$ Lead, and mostly harvested from Abakaliki, Ebonyi State, Nigeria[11]. Black Antimony, applied to the eyes as ground, fine crystalline powder with the aid of thin stick, is used to draw a straight line on the eyes.The application of these mineral locally to the eyes is believed to serve as treatment of ophthalmologic infections and as an eye cleanser [9]. The use of the local eye liner has been reported as a suspected source of Lead exposure to the ocular system in children and adults [12].

Calabash chalk also known as Calabarstone is an ancient cosmetics used by Nigerian women. This natural cosmetic is made up of fossilized seashells, mixed with clay mud and other ingredients such as sand, wood ash, and sometimes salt [13]. The calabash chalk is ground into a fine powder and rubbed on the face as facial powder and antiperspirant which makes the face to remain dry [14].

The use of cosmetics by Nigerian women is an ancient tradition. Women, young and old, apply and beautify themselves with cosmetics of different texture and colours, especially during festive periods.Cosmetics are believed to improve the best features and cover the blemishes on the person wearing them.

Some factors such as advertisement,peerpressure andsocial acceptance, influence the choice of skincare products applied by most women. A study conducted by Robertsonet al., [15] revealed that women who apply make-up are insecure, anxious and not confident about themselves.

Cosmetic products contain varieties of different harmful or toxic chemicals capable of attacking the skin. Manufacturers of skincare productsdo not only use synthetic ingredients but also natural products, such as Shea butter, Rose extract, and cane sugar which are sustainable,cheap and less harmful to the consumer [16].

\section{Side Effects of Cosmetics}

Skincare products such as perfumes, make up, nail polish, etc, can cause allergic reactions and skin irritation; these products can remain on the body for a long period of time and cause significant adverse reactions [17, 18]. Moisturizers increase the hygroscopic properties of the skin particularly when the concentration of these substances is high in the body. It can cause irritation and exfoliation. Skin lightening agents such as hydroquinone (HQ) is one of the most harmful chemicals. However, there have been reports of ochronosis and potential mutagenicity. Ochronosis is an uncommon adverse effect of $\mathrm{HQ}$, characterised by progressive darkening of the area to which the cream containing high concentrations of HQ is applied for many years (19).

Black henna tattoo is a chemical stain due to pphenylenediamine (PPD), in the form of commercial hair dye mixed into the henna paste. Negative effect of PPD may include, blisters and surface oozing, swelling, erythematous rash. Studies have been made and reports given about the immediate allergic reactions on using henna dyes. Most cases involve sneezing, runny nose, cough and shortness of breath instead of skin reaction [19].

Sun-screening agents can cause irritant, allergic, phototoxic or photo-allergic reactions. Benzophenones are the most common sensitizers, while debenzoylmethanes, para-aminobenzoicacid (PABA) and cinnamates may cause photo-allergic dermatitis [20].

The allergic reactions associated with deodorant/anti perspirants and fragrances are mostly caused by the fragrance or other ingredients. Fragrances can enter the body through skin(adsorption), lungs, air ways, ingestion and through pathways from the nose directly to the brain and can cause headaches, dizziness, fatigue, irritation to eyes, nose and throat, forgetfulness and other symptoms. Fragrances sprayed in the air or found in air can cause air-borne contact dermatitis. Chemicals like coumarin, phethleugenol found in fragrances are suspected carcinogens, while phthalates are suspected hormones disrupters [21].

Shampoos and conditioners do not have much contact with the skin; they are only applicable to the hair and as such, cause less adverse effect. However, they can be a problem when they come in contact with the eyes during washing of the hair. The most common effect of using shampoo is the matting of the scalp hair (also refered to as tangling of hair) [22].Active ingredients in hair bleaching product such as Hydrogen peroxide solutions, and Ammonium persulfate, may cause Types I and IV allergic contact reactions.

\section{Health and Environmental Hazards of Some Chemicals in Cosmetics}

BHA (butylatedhydroxyanisole) and BHT (butylatedhydroxytoluene) are closely related synthetic chemicals used as preservatives in moisturizers and lipsticks, among other cosmetics.BHA and BHT can cause allergic reactions in the skin. The International Agency for Research on Cancer has classified BHA as a possible human carcinogen. The European Commission on Endocrine Disruption has also listed BHA as a Category I priority substance, based on evidence that it interferes with hormone function [23]. BHT may act as a tumour promoter in certain situations. Limited evidence suggests that high doses of BHT may mimic oestrogen, the primary female sex hormone, and prevent expression of male sex hormones, resulting in adverse reproductive affects [23].

\subsection{Coal Tar Dyes}

Coal tar is a mixture of many chemicals, from petroleum. Coal tar-derived colours are used mostly in cosmetics, generally identified by a fivedigit Colour Index (CI) number. The p-phenylenediamine is a particular coal tar dye used in many hair dyes. Darker hair dyes tend tocontain more phenylenediamine than lighter colours. 
Coal tar is associated with cancer and the main concern with individual coal tar colours (whether produced from coal tar or synthetically) is the possibility of them to cause cancer. These colours may be contaminated with low levels of heavy metals and some are combined with Aluminum substrate. Aluminum compounds and many heavy metals are known to be harmful to the brain. Some of these colours used to produce these dyesare not approved as food additives, yet they are used in cosmetics that may be ingested, like lipstick. P-phenylenediamine has been found to be carcinogenic [24]. Zhang [25] has established that women who use hair dyes especially over a long periodhave increased risk of developing non-Hodgkin's lymphoma (cancer of the lymph system). The European Union classifies p-phenylenediamine as toxic (whether by contact, inhalation, or by ingestion) and as very toxic to aquatic organisms, as it may cause long-term adverse (chronic) effects in the aquatic environment.

\subsection{DEA (Cocamide DEA and Lauramide DEA)}

DEA (diethanolamine) related ingredients are used to make cosmetics creamy or sudsy, or as a $\mathrm{pH}$ adjuster to reducethe acidity of other ingredients. They can be found in shampoos, soaps and cleansers.DEA reacts with nitrites in cosmetics to form nitrosamines. Nitrites are sometimes added to products as anti-corrosive agents or can be present as contaminants [25]. The deterioration of some chemicals used as preservatives in cosmetics can release nitrites when the product is exposed to air. In laboratory experiments, exposure to high doses of DEA-related ingredients has been shown to cause liver cancers and precancerous changes in skin and thyroid. These chemicals can also cause mild to moderate skin and eye irritation. Cocamide DEA is known as hazardous to the environment because of its acute toxicity to aquatic organisms and can bioaccumulate [25].

\subsection{Dibutyl Phthalate (DBP)}

DBP is used mainly in nail products as a solvent for dyes and as a plasticizer that prevents nail polishes from becoming hard and easily broken. It has been shown to cause developmental defects, changes in the prostate and testes and reduces sperm counts [26]. It has also been classified as a suspected endocrine disruptor on the fact that it interferes with hormone function, and may cause harm to the unborn child and worsen infertility. Furthermore, Health Canada reveals that exposure to phthalates may pose health effects such as liver and kidney failure in young children when products containing phthalates are ingested for extended periods $[27,28]$. Phthalates have been linked to reduced sperm count in men and reproductive defects in the developing male foetus (when the mother is exposed during pregnancy), among other health effects.

\subsection{Parabens}

Parabens are the most commonly used preservative in cosmetics. An estimated 75 to 90 per cent of cosmetics contain parabens (typically at very low levels). Parabens easily penetrate the skin and are suspected of interfering with hormone function (endocrine disruption). They can mimic oestrogens, the primary female sex hormone. They can as well interfere with male reproductive functions. In addition, studies indicate that methylparaben applied on the skin reacts with other chemicals, leading to increased skin aging and DNA damage [29]. Parabens occur naturally at low levels in certain foods, such as barley, strawberries, carrots, onions currents, and vanilla, although a synthetic preparation derived from petrochemicals is used in cosmetics[30]. Parabens in foods are broken down when eaten, making them less strongly estrogenic. In contrast, when applied to the skin and absorbed into the body, parabens in cosmetics bypass the metabolic process and enter the blood stream and body organs intact. It has been estimated that women are exposed to $50 \mathrm{mg}$ per day of parabens from cosmetics [30]. They are associated with cancer and neurotoxicity among other adverse health effects[31].

\subsection{Perfume (Fragrance)}

The term perfume (fragrance) on a cosmetic ingredients list usually represents a complex mixture of many chemicals. Some 3,000 chemicals are used as fragrances. Fragrance is an obvious ingredient in perfumes, deodorants and colognes. It is used in nearly every type of skincare product. Even products marketed as "fragrance-free" or "unscented" may contain fragrance ingredients in the form of masking agents that prevent the brain from perceiving odour [27]. Many of unlisted fragrance ingredients are irritants and can cause allergies, severe headache and asthma symptoms.Perfume can worsen asthma and perhaps even contribute to its development in children. It is ranked the second most common cause of allergy in patients [32].

\subsection{Polyethylene Glycols (PEGs)}

Polyethyleneglycols (PEGs) are petroleum-based compounds that are widely used in creams as thickeners, solvents, softeners and moisture-carriers. Depending on the production processes, PEGs can be contaminated with measurable amounts of 1,4-dioxane. According to the, 1,4dioxane has been suspected to be carcinogenic.It does not easily degrade and can remain in the environment long after it is rinsed down the shower drain [21]. PEGs show some evidence of genotoxicityand if used on broken skin can cause irritation and systemic toxicity.

\subsection{Petrolatum}

Petrolatum serves as a barrier to lock moisture in the skin in a variety of moisturizers. It is used in hair care products to make hair shine. It is also known as mineral oil jelly.Petrolatumcan be contaminated with polycyclic aromatic hydrocarbons (PAHs). Studies have shown that exposure to PAHs - including skin contact over a long period of time - is connected with cancer. On this basis, the European Unioncategorise petrolatum as a carcinogen and 
restricts its use in cosmetics. PAHs in petrolatum can also cause allergies and skin irritation [33].

\subsection{Siloxanes}

These are silicone-based compounds used in cosmetics to soften, smoothen and moisten skincare product. They make hair products dry faster and deodorant creams slide on more easily. They are mostly used in moisturizers and facial treatments. Cyclotetrasiloxane and cyclopentasiloxane knownare toxic, persistent and have the potential to bioaccumulate in aquatic organisms. Cyclotetrasiloxane is classified as an endocrine disruptor, as it interferes with human hormone function, and as possible reproductive toxicant, may impair human fertility[34].

\section{Health Risk Associated with Heavy Metals in Cosmetics}

Heavy metals have been implicated in cosmestics commonly used among women [35, 36]. Again, hazards associated with heavy metal in facial make-ups have been discussed in literatures [37]. Heavy metals which can build up in the body over time are known to cause various healthproblems, such as; cancer, reproductive and developmental disorders, neurologicalproblems; cardiovascular, skeletal, blood, immune system, kidney and renal problems; headaches; vomiting, nausea and diarrhoea;lung damage; contact dermatitis; and brittle hair and hair loss. Some are hormonedisruptors while others are respiratory toxins. However, for some like Lead, there is no known safe blood level. They can be ingested or absorbed through the skin, especially broken skin [38].

\subsection{Cadmium}

Cadmium occurs naturally in the environment. Cadmium found in body and hair creams are absorbed into the body through dermal contact [39]; stored in the kidney andthe liver, although it can be found in almost all adult tissues. It is considered to be "carcinogenic to humans" by the IARC [40] and its compounds, categorized as known human carcinogens by the United StatesDepartment of Health and Human Services [41]. Ingestion of high levels of cadmium can lead to severe stomach irritation, vomiting and diarrhoea, while exposure to lower levels for a long time can lead to kidney damage, bone deformity, and the ability of bones to break easily [41].

\subsection{Lead}

Lipstick can becomecontaminated with Lead via the use of contaminated raw materials or through the use of pigmentsthat contain it [42]. Skin contact with Lead occurs daily, and some have been found to be absorbed throughthe skin [27]. The use of leaded eye powders (e.g., Surma, Kohl, Alkol) hasbeen associated with increased blood-Lead levels in children andwomen [43]. Pregnant women and young children are particularly vulnerablebecause it can cross the placenta with ease and enter the foetalbrain [42]. It can also be transferred to infants through breastfeeding [44] and stored in bones [45]. Lead exposure hasalso been linked to miscarriage, hormonal changes, reduced fertility in men and women, menstrualirregularities, delays in puberty onset in girls [42]. Lead and inorganic Lead compounds have beenclassified as a suspectedcarcinogenic to humans [40].

\subsection{Nickel}

Due to the abundance of this metal in nature, everyone is exposed to small amounts, mostly through food, air, portable water, soil, household dust, and skincontact with products containing it, including cosmetics [27, 41]. Highlevels of exposure can lead to health effects depending on route and the kind of nickel exposedto [27]. While certain types of Nickel are considered to be "toxic" because of their carcinogenicity, metallic Nickel and alloys have been classified as possibly carcinogenic to humans [40]. Allergy to Nickel is also commonand it can cause severe contact dermatitis [27]. The first case of Nickel allergy causedby eye shadow has been reported; even as $1 \mathrm{ppm}$ of it may trigger a pre-existingallergy [38].

\subsection{Mercury}

Mercury is a common ingredient found in skin-lightening soaps and creams.It is also found in other cosmetics, such as eye make-up, cleansing products and mascara. Skin-lightening soaps and creams are mostly used in certain African and Asian countries. They are also used among dark-skinned populations in Europe and North America [46].

Mercury salts inhibit the formation of melanin, resulting in a lighter skin tone. Mercury in cosmetics exists in two forms: inorganic and organic. Inorganic mercury (e.g. ammoniated mercury) is used in skin-lightening soaps and creams. Organic mercury compounds (ethyl mercury and phenyl mercuric salts) are used as cosmetic preservatives in eye make-ups, cleansing products and mascara.The main adverse effect of the inorganic mercury contained in skinlightening soaps and creams is kidney damage [46].

Mercury in skin-lightening products can also cause skin rashes, skin discoloration and scarring, as well as a reduction in the skin's resistance to bacterial and fungal infections. Other effects include anxiety, depression or psychosis and peripheral neuropathy. Mercury in soaps, creams and other cosmetic products is eventually discharged intowastewater. The mercury then enters the environment, where it becomes methylated and enters the food-chain as the highly toxic methylmercury in fish. Pregnant women who consume fish containing methylmercury transfer the mercury to their foetus, which can later result in neuro-developmental deficits in the children [46].

\section{Conclusion}

Although, cosmetic products are not often associated with serious health hazards, this does not mean that they are 
always safe to use, especially with regard to possible longterm effects as the products may be used extensively over a long period of time.Cosmetics and skincare products may contain ingredients whose safety is not certain or which are known to cause health risks.Many of the cosmetics, particularly hairdyes and shampoos may contain ingredients classified as known or probable human carcinogens. Again, many of these products may contain penetration enhancers, increasing penetration through the skin.

In Nigeria, the agenciesthat control the safety of cosmetic products are working hard to ensure safety of the consumers of these products; the manufacturers of these products on their part have the responsibility to ensure the clinical safety of their products.

\section{References}

[1] S.K. Singh, Handbook on Cosmetics (Processes, Formulae with Testing Methods). Asia Pacific Business Press Inc., 2010, pp.688.

[2] A. Claeyssens, "The History of Cosmetics and Make up," http://ezinearticles.com/?The-History-of-Cosmetics-\&makeup\&id=1857725, 2009.Retrieved, February 28, 2015.

[3] G. Schneider, S. Gohla, J. Schreiber, W. Kaden, U. Schomock, et al., "Skin cosmetics,"Ullmann's Encycl. Ind. Chem, 2001, vol. 10: 24-219.

[4] M. Price, "Cosmetics, Styles \& Beauty Concepts in Iran," http://www.iranchamber.com/culture/articles/cosmetics_beaut y.php, 2001. Retrieved, February 20, 2015.

[5] K. B. Patkar, "Herbal cosmetics in ancient India," Indian Journal of Plastic Surgery, 2008, Vol. 41: S134-S137.

[6] A.D. Hardy, R. Vaishnav, S.S. Al-Kharusi, H.H. Sutherland and M.A. Worthing, "Composition of eye cosmetics (kohls) used in Oman," Journal of Ethnopharmacology, 1998, vol. 60(3):223-234.

[7] A. Hardy, R. Walton and R. Vaishnav, (2004). "Composition of eye cosmetics (kohl) used in Cairo," International Journal ofEnvironmental Health Research, 2004; 14(1): 83 - 91.

[8] O.M. Badeeb, R.S. Ajlan and M.H. Walid, Kohl Al-Ethmed. Acute toxic effects of fragrance products. JKAU: Medical Science, 2008, vol. 15 (4): 59-67.

[9] C.S. Chukwuma, "Environmental Lead exposure in Africa," Ambio, 1997, vol. 26(6):399-403.

[10] A.O. George, A.O. Ogunbiyi and A. O. M. Daramola, "Cutaneous adornment in the Yoruba of south-western Nigeria - past and present," International Journal of Dermatology, 2006, vol. 45: 23-27.

[11] V. Biringuccio, "The Pirotechnia Vannoccio Biringucco," translated by Smith, S.C. and Gnudi, M.T. Dover Publications, 1990 (incomplete).

[12] K. Gibbs, "The Importance of Cosmetics and Make-up," Ezine articles. http://ezinearticles.com/?The-Importance-OfCosmetics-And-Make- Up\&id=827832， 2007. Retrieved, February 28, 2015.
[13] J. Dean, "Skin health: Prevention and treatment of skin breakdown," Transverse Myelitis Assoc. Journal, 2011, vol. 5.

[14] E.G. Ekosse, and N.D. Jumbam, "Geophagic clays: Their mineralogy, chemistry and possible human health effects," African Journal of Biotechnology, 9(40):6755-6767.

[15] J. Robertson, G. Fieldman and T.B. Hussey, "Who wears cosmetics? Individual differences and their relationship with cosmetic usage," Individual DifferRes, 2008, vol.6: 38-56.

[16] A. Rinaldi, "Healing beauty? More biotechnology cosmetic products that claim drug-like properties reach the market," EMBO Rep, 2008, vol.9: 1073-1077.

[17] P.K. Nigam, "Adverse Reaction to cosmetics and method of testing," Indian J Dermatol Venerol Leprol, 2009, vol. 75(1): $10-19$.

[18] N.C. Shalom, E.A. Dominic, C.O. Victor, E.J. Iweala, S.I. Afolabi, C.C. Uhuegbu, and S.U. Oranusi, "Skincare product usage; implication on Health and wellbeing of Africans," Journal of Applied Science, 2013, vol. 13(3): 430-436.

[19] P.K. Nigam and A.K. Saxena, "Allergic contact dermatitis from henna," Contact Dermatitis, 1998; 18:55 - 6 .

[20] J.D. Johansen, S.C. Rastogi and T. Menne, "Threshold responses in cinnamic-aldehyde-sensitive subjects: Results and methodological aspects," Contact Dermatitis, 1996; 34:165-71.

[21] B. Bridges, "Fragrance: emerging health and environmental concerns," Flavour Fragrances Journal, 2002; 17:361-71.

[22] C.L. Wilson, D.J. Ferguson and R.P. Dawber, "Matting of scalp hair during shampooing: A new look," Clin. Exp. Dermatol., 1990; 15:139- 142.

[23] T.J. Schrader and G.M. Cooke, "Examination of selected food additives and organochlorine food contaminants for androgenic activity in vitro." Toxicological Sciences, 2008; 53(2): 278-88.

[24] D.E. Rollison, K.J. Helzlsouer. and S.M. Pinney, "Personal hair dye use and cancer: a systematic literature review and evaluation of exposure assessment in studies published since 1992." Journal of Toxicology and Environmental Health Part B: Critical Review, 2006; 9(5):493-500.

[25] Y. Zhang, "Personal use of hair dye and the risk of certain subtypes of non-Hodgkin lymphoma." American Journal of Epidemiology, 2008; 167(11):1321-1331.

[26] N.J. Barlow, B.S. McIntyre and P.M. Foster, ".Male reproductive tract lesions at 6,12 , and 18 months of age following in utero exposure to di(n-butyl) phthalate," Toxicology Pathology, 2004; 32(1): 79-90.

[27] Health Canada, "Report on Human Biomonitoring of Environmental Chemicals in Canada: Results of the Canadian Health Measures," Survey Cycle 1 (2007-2009), Ottawa, 2010 .

[28] R.W. Stahlhut, "Concentrations of urinary phthalate metabolites are associated with increased waste circumference and insulin resistence in adult U.S. males," Environmental Health Perspectives, 2007; 115:6.

[29] P.D. Darbre, "Concentrations of Parabens in human breast tumours," Journal of Applied Toxicology, 2004; 24(1): 5-13. 
[30] G. Vince, "Cosmetic chemicals found in breast tumours," New Scientist,http://www.newscientist.com/article/dn4555cosmetic-chemicals-found-in-breast-tumours.html, 2004. Retrieved, March 15, 2015.

[31] R.C. Anderson and J.H. Anderson, "Acute toxic effects of fragrance products," Archives of Environmental Health, 1998; 53(2): $138-46$.

[32] International Agency for Research on Cancer, "Agents Classified by the IARC Monographs, Volumes 1-100," http://monographs.iarc.fr/ENG/Classification/index.php, 2010. Retrieved Februray 28, 2015.

[33] G. Ulrich, "Sensitaization to petrolatum: an unusual cause of false-positive drug patch-tests," Allergy, 2004; 59(9): 10061009.

[34] V. Niel, "Top 10 Harmful Effect of Using Cosmetics," list Crux.4, http://www.list crux.com/top-10-harmful-effects-ofusing-cosmetics, 2014. Retrieved March 10, 2015.

[35] O.E. Popoola, M.A. Bisi-johnson, A. Abiodun and O.S. Ibeh, "Heavy metal content and antimicrobial activities of some naturally occurring facial cosmetics in Nigeria," Ife journal of science, 2013; 15(3): 637-644.

[36] S. Ramakant, S. Poornima, J. Sapina, H.B. Mathur and H.C. Agarwal, "Heavy metal in cosmetics," Centre for science and Environment, 2014; 45: 3-28.

[37] Environmental Defence, "Heavy metal hazards; the health risk of heavy metal in face hidden make up," http://environmentaldefence.ca/sites/default/files/report_files/ HeavyMetalHazards\%20FINAL.pdf, 2011. Retrieved, February 23, 2015.
[38] E.L. Sainio, R. Jolanki, E. Hakala and L. Kanerva, "Metals and arsenic in eye shadows," Contact Dermatitis, 2001; 42 (1): $5-10$.

[39] J.G. Ayenimo, A.M. Yusuf and A.S Adekunle, "Heavy Metal Exposure from Personal Care Products," Bulletin of Environmental Contamination and Toxicology, 2010; 84 (1): 8-14.

[40] Agency of Toxic Substances and Disease Registry, "Toxicological Profile for Cadmium," http://www.atsdr.cdc.gov/toxprofiles/tp.asp?id=48\&tid=15, 2008. Retrieved, March 10, 2015.

[41] Campaign for Safe Cosmetics, "Lead in Lipstick," http://www.safecosmetics.org/article.php?id=223, 2007 , Retrieved, Febuary 282015.

[42] R.V. Sprinkle, "Leaded eye cosmetics: a cultural cause of elevated Lead levels in children," Journal of Family Practice, 1995; 40 (4): 358 - 362.

[43] Agency of Toxic Substances and Disease Registry, "Toxicological profile for Lead," http://dwww.atsdr.cdc.gov/toxprofiles/tp.asp?id=96\&tid=22, 2007. Retrieved, March 10, 2015.

[44] S.J. Rothenberg, F. Khan, M. Manalo, J. Jiang, R. Cuellar, S. Reyes, et al. "Maternal Bone Lead Contribution to Blood Lead during and after Pregnancy," Environmental Research, 2000, 82(1): 81-90.

[45] World Health Organization (WHO), "Mercury in skin lightening product. Geneva, world health organization (preventing disease through healthy environment series)," http://www.who.int/phe/new/mercury-flyer.pdf, 2007, Retrieved, February 20, 2015.

[46] K.A. Biebl and E.M. Warshaw, "Allergic contact dermatitis to cosmetics," Dermatol Clin, 2006, vol. 24: 215-232. 